\title{
A FEW CRITICAL COMMENTS TO THE PAPER BY MAREK LOUŽEK: THE ECONOMIC APPROACH TO SCIENCE
}

\section{Jan Ámos Víšek*}

"We keep, in science, getting a more and more sophisticated view of our essential ignorance."

Warren Weaver ${ }^{1}$

More than a year ago I was asked by the Editor of Prague Economic Papers to write an opponent review on the paper by Marek Loužek "The Economic Approach to Science"2. The paper was devoted to a new, modish theory explaining what the science really is that it is a collection of human activities oriented on selling new ideas and/or personalities of scientists in order to produce a maximal (financial) profit, i.e. the science is in fact a branch of market economy (or at least it behaves as the market economy). When the review was delivered, the Editorial Board decided that it may be interesting for readers to compare points of view of researchers from different branches of science. So, they offered me to publish the opponent report.

The reader would have a possibility to see, on the one hand, the point of view by Marek Loužek, the economist - who has very intimate (tight, if you want) proficiency of the topic and hence his interpretation of the ideas of this new branch can be supported by large knowledge from economics. On the other hand - the point of view of the mathematician, who is not a specialist in the economics but who shares - as I believe - the common ideas about the science and its philosophy with researchers from natural sciences. I do believe in coincidence of my point of view on ideas about the science, what it is and what it is not with ideas of many researchers in natural sciences. I am not so sure about the latter part of previous sentence. In some philosophical point of view I can see the science in a bit different way than (many?) my colleagues from natural science. It is (at least partially) due to the fact that I spent more than 20 years among the social scientists. It is (also partially) due to my (amateur) interest in philosophy of sciences which started when the journal

* Jan Ámos Víšek, Institute of Economic Studies, Faculty of Social Sciences, Charles University, Prague, Czech Republic (visek@fsv.cuni.cz).

Research was supported by the Grant of the Czech Science Foundation Project No. P402/12/G097 "DYME - Dynamic Models in Economics" Prague, August 20, 2015.

1 Warren Weaver was an American mathematician and science administrator. He was known as an unconditional and passionate supporter of science and widely recognized as a pioneering person of research on the possibility of machine translation. Beyond the others, he developed the philosophical implications of Shannon's theory.

2 In what follows for the sake of space and also for a more plausible reading this collection of remarks and comments, the paper written by Marek Loužek will be referred to as paper, i.e. the word "paper" will be written hereafter in italic. 
"Advances of Mathematics, Physics and Astronomy" published the translation of paper by Iliya Prigogine and Isabelle Stengers (1977) ${ }^{3}$.

However, personally I am sure that it is just the philosophy, especially the modern philosophy of science which is to say - or even has to say - a lot to the problems discussed in the paper. Anyway, what I would like to stress - the idea to write this paper was not mine and I apologize to readers - especially to philosophers of science - if they will be shocked by (a naivety of) some ideas below.

Although my point of view (on scientific, philosophical, theological, etc. problems) will be (at least partially) traceable from the text below, I assume that it would be useful to say something in advance - to give the readers some guide or a hint how to understand some abbreviatory (or even compressed, if you want) text below ${ }^{4}$. Although some notions as objectivity, truth, etc. were never explicitly mentioned or discussed in the paper, the sense and/ or interpretation of the text of paper depends in fact very much on the content we assume they have. Without an attempt to specify (or even define) them in a more or less "rigorous" way, one can understand the paper in various, rather different ways. The present text then can be viewed as a discussion with one such possible interpretation of the paper, my interpretation, and I have to admit that it may be interpretation quite different from Marek Loužek 5

Following (many) other authors (see e.g. Vácha, 2012, 2014) the present author believes that there are three (main) collections of tools for describing the world - the science, metaphysics and arts. Notice please that in the previous sentence $\mathrm{we}^{6}$ have not used the verb "explain" (but the verb "describe") and the reason for it will be clear from what follows.

The first collection of tools - the science - has its roots in the ancient philosophy (especially such parts of ancient philosophy as mathematics, geometry, astronomy, etc.)

3 The paper could not be published in the Czechoslovakia during the normalization period but it escaped - due to the name and orientation of the journal - to the attention of censors.

4 It is, however, clear that no narrative text can reach the exactness and correctness of formalized explanation of logical steps, proving an assertion. And it is also clear that e.g. to explain the ideas of paper in a formalized way would be labour-intensive (and at the first glance nearly impossible) task for author. But then it is necessary to put up with the fact that the narrative text cannot give an unambiguous information about the ideas which Marek Loužek wanted to convey to reader. In the light of the character of present economic papers which - even in the case when they employ some econometric methods - are frequently written (except of some really good, theoretical journals) in an "econometric-like slang", i.e. in mostly narrative way avoiding the structure of (mathematical) text: definition, theorem, proof, remark, etc., the present paper seems to be quite in the acceptable limits.

5 The possibility of various interpretation of the text is of course an example showing that any narrative text loses, more or less, the scientific character. Although we have abandoned the Renaissance chimera of objectivity of science, I believe that the most of readers would agree with me that the science should be neutral with respect to our philosophical, religious, ideological etc. points of view. On the other hand, it should offer texts which are unambiguous. Maybe that such an ideal form of text can be reached only by formalized text. It, of course, does not mean that the narrative text cannot be scientific - very first attempt of specifying a problem can reach the ideal, the unambiguous form only rarely. But the unambiguity, the neutrality with respect to some (ideological, philosophical, political, religious, etc.) doctrine should be the ideal for the scientific text we are to try to achieve.

6 In mathematics people are used to write the papers in the first person of plural (although the most of papers were written by one author), just saying e.g.: We have defined continuous function as ... . This tradition tries (perhaps) to indicate that the definition of continuous function is not invention or proposal of given author but is usually used in this form. We will keep this tradition when it will be appropriate. In the present case, "we" indicates that I cannot make any claim of priority of creating such a point of view on basic tools for a description of world. 
but its character as we know the science today (or as it was more or less without hesitation accepted nearly up to the half of past century) was established in the Renaissance and the Age of Enlightenment, see e.g. Atalay (2006). The main idea was to substitute the "dogma of metaphysics" (i.e. "revelational truth") by common sense and so to get into a God-like position, being able to explain (notice that now the word "explain" was used) everything without any prior belief(s). It was a contradictory idea from the very start because the key belief of such an approach was that some natural laws exist as such (probably invented by God prior to the moment at which he turned on the Big Bang) and that the science is a tool how to discover them, in a very similar way as Christopher Columbus discovered America or as we can learn what is inside the onion when we peel out its skin. Personally I do not believe that the philosophy of science can prove anything like this. I do not believe that any attempt to explain the character of existence of such laws could be coercive, at least on the level of explanation of existence of time, see Prigogine (1982) and his arguments about reversible and irreversible processes. Personally I believe that such laws are some "projection limits" of (many) events which can be - by some steps of abstraction - "bundled" together, see the discussion of the notion of gravitation below. Of course, such point of view is not very far from the doctrine which is in philosophy of science called instrumentalism.

Nowadays, it is clear that Renaisance idea of explaining the world failed. It failed not only as the idea to use the common sense without any prior belief ${ }^{7}$ but it failed as the idea of possibility to explain the world ${ }^{8}$. We humbly return to position which admits that we never be God and that we never learn "how the world really is". All after, it was the wholelife discussion between Albert Einstein and Niels Bohr. Niels Bohr tried to explain to Albert

$7 \quad$ E.g., personally I assume that if I measure some length two times and I expect that I obtain just two same results (leaving aside for a moment the measurement error), I assume that this expectation is already a step of a prior belief. It seems to me that there is no reason why I should obtain the same result, just only my belief that it should happen. In mathematical language I would say that we need an axiom that two measurements of the same length give the same result. I remember that when I asked (on the base of recommendation of Václav Dupač) Petr Vopěnka for a help with solving an exercise in Hewitt-Stromberg book, his answer was: Can I use the axiom of selection? In other words, although the common sense or common belief naturally assumes that having a set of points we are able to select one point, mathematicians realized that it is not so clear that we really can do it and that any such action is in fact a step of belief and formulated it as the axiom of selection. If we admit it, we are only a step from accepting the idea that we can base the whole science on various collections of axioms. It allows to avoid the word "belief" because the axiom is purely abstract thing, it is an assumption and the employment of word "axiom" is to indicate that it is some basic assumption. Moreover, it hints that our (scientific) theories are completely neutral with respect to our philosophy, religion, ethics, etc. What does depend on our philosophy, religious orientation, ethic etc. is a (or the?) belief that given theory (based on a collection of axioms) is appropriate for given situation, for given data, under given circumstances, etc. Further discussion of this idea is below.

8 It is easy to show that the common sense - which is a collection of prejudices, misbeliefs, folklore "scientific" ideas, etc. - is unreliable tool. One can easy construct a function $\mathrm{f}:[0,1] \rightarrow[0,1]$, $\mathrm{f}(0)=0, \mathrm{f}(1)=1$ which is continuous and constant on the whole interval $[0,1]$. By a common sense we cannot accept anything like this. Similarly, in a fence we have between any two bars at least one gap and between any two gaps at least one bar. We know by experience that then the number of gaps and bars differ about one, i.e. the number of bars and number of gaps are approximately the same. Applying this idea on the rational and irrational numbers, we confirm that between any two rational numbers we have at least one irrational and between any two irrational numbers we have at least one rational. But any student of secondary school knows that we have much more (even infinitely more) irrational numbers than rationals - the common sense failed. 
Einstein - who believed that the world is deterministic - that we cannot really learn whether the world is deterministic or not because what we observe and what we try to describe or even explain by (narrative as well as formalized) models is already some intuitively created "picture of world", i.e. some intuitively constructed vague model of world, although such an intuitive, in many cases even not consciously described model is very far away from a formalized one. In fact, without some preconceptions, (mis)beliefs, prejudices etc. we cannot even observe the world around us at all ${ }^{9}$. Of course, without focusing on the problem of observing the world, we even do not realize that we do not observe the world directly but some "picture of world" because we do not realize how much preconceptions and "natural" beliefs we have overtaken from our parents in the very first years or even months of our life.

What may be of interest, Niels Bohr moreover claimed - and the modern science tends to confirm it more and more - that our models are to be stochastic ones, i.e. the models should contain some element of uncertainty (not necessarily using the probability theory and/or statistics). Of course, it depends on accuracy with which we measure the reality. In some cases the random fluctuations are so small that the measurement has to be so "microscopically" exact that it would be either impossible or even absurd to incorporate these fluctuations into our model.

Taking into account what was already said and making some (I believe) small step of abstraction, we can imagine the science as a collection of axioms, rules of formal logic, definitions, theorems, assertions, etc. all of them completely abstract, i.e. having nothing to do with the real world, having nothing common with our personal beliefs, philosophy, religion, etc. In other words, we would have a system of (all possible) formalized models which can be then applied on the real world (of course, to be really exact we should say can be then applied on the pre-concepted picture of real world, as it was explained above) - naturally not in order to explain the world (we have indicated above that it is impossible) but to control it, to forecast its development with being successful in statistically significant number of trials, and so to degrease appearance of diseases, to decrease poverty, etc. We should add that we are to be aware of some limits of such an abstract concept, the limits given by famous Kurt Gödel's incompleteness theorems, see Gödel (1931). It is clear that this first system of tools - the scientific models - has of course some serious limits (or if you want, constraints) of "explanation" and we need the other two collections of tools for describing the world - the metaphysics and arts. We need the metaphysics to be able to cope with problem why we feel to someone love or friendship or why we assume something to be ethical or moral. Similarly the third system, the arts, is intended to deal with beauty and plausibility, harmony and mood, etc. If we have a bit more imagination ${ }^{10}$, we can assume the second and the third system - the metaphysics and the arts to be also an axiomatic systems which then individuals apply on the "real world" - being aware that the responsibility for such application is fully on the applicator. However, we should be also aware that we cannot freely move the notions from one system to another without a danger that we obtain some

$9 \quad$ Without some $a$ priori made ideas, some prefabricated concepts of world we cannot decide which feature of it we should observe, what devices we should construct, etc. E.g. why we measure distances or weights - because it appeared to be practical and useful. But what is practical and useful depends on our scale of values, our evaluation what is successful, etc. and the chain of arguments can continue without leading to a reasonable justification and finally it is based on some steps of belief.

10 Karl Popper once wrote that if we cannot imagine that something can be so and so, it is not due to the fact that it cannot be so but it is lack of our imagination. 
nonsense. E.g. probably most of us accepts in science relatively common system of axioms leading to the conclusion that the scientific models and their applications in the real world (as we already said, in order to describe how the world works and to predict how it will develop in future) should be unbiased, neutral from ethical, moral or religious point of view etc. On the other hand, in the metaphysics we accept that the religious, political and in some limits, ethical or moral system of axioms can be freely selected by individuals ${ }^{11}$. The largest freedom will be probably (surely?) accepted in the third system - in arts. It is well known proverb that there is no discussion with the taste.

The last (but not least) remark is that this paper was written as a review or discussion to the draft of paper as it was submitted to the journal. I assume that some places were modified due to my opponent review. Despite it, the main spirit of paper will be probably preserved because it expresses point of view of its author. That is why I decided (and frankly speaking, I had no other possibility) to keep the authenticity of review transformed into this discussion, I will keep the pagination of draft (when referring to given places of the text of draft of paper) although I realize that it is not valid (as the draft was surely modified).

The paper discusses in details an analogy to the sociology of scientific knowledge the economic approach to science. The paper has brought a lot of supporting arguments and it is clear that the author had devoted quite large effort to collect them. Nevertheless, I think that the reader cannot get rid of idea that the "whole story" (similarly as in the case of sociological approach) is a modish matter ${ }^{12}$.

11 Some of us accept e.g. as a system of axioms Ten Commandments, some of us not.

12 It is nothing new in science, even in "exact" parts of science. People, feeling that something is modish, start to write papers without having appropriate knowledge and understanding of tools for it, employing a "mathematical slang" or "folklore". E.g., when people started data-mining or neuron networks, they tried (mainly) to create a software, by trial-fail method, without solving any question of asymptotics, i.e. question of reaching the true underlying model. Notice that in the previous sentence true was used without converted commas because the "whole story" can (and I think, hypothetically should) run inside mathematical framework, i.e. on a completely abstract level without any connection with the real world. Our models - in just explained way (or conception) of creating the formalized models - start to have a connection with the real world at the moment when somebody applies them on the real world in order to solve something, e.g. to predict the GDP for the next year, to establish some diagnosis, decide for some social politics, etc. But then the whole responsibility (or accountability, if you want) "falls" on that person who utilizes this model.

Of course, it is still so that (many?) researchers (intuitively and/or tacitly) believe that they describe and explain directly (and even objectively) the world. They believe that their assumptions (axioms) really "hold" (or at least "approximately hold") and that then their theories describe and/ or explain the world as it is (at least approximately). Sometimes, they do it in the situation when they are aware that their assumptions are problematic. They just try to see what the result will be - they hope that even then the result can appear reasonable or acceptable in common sense. Then it can result in models which are strange (modestly saying). We cannot be then astonished that there appeared the statement: Modelling the capital markets made from the astrology respectable science.

On the other hand, when we leave all responsibility (or accountability) for application of theoretical tools on a person who applies them, it can yield remark: People use more and more frequently more and more sophisticated methods with less and less understanding to them. (I admit that I forgot who said it, whether James Heckman or Robert Engle or some other Nobel prize winner).

Maybe that the worst approach to "explanation" of world is to building models by "experimenting" on the computer. Paul Halmos (1981), one of the best American mathematicians, devoted to it the paper Applied Mathematics is a Bad Mathematics. He explained in it that making any model without the deep understanding of theoretical mathematical background, i.e. not keeping the traditions started by ancient mathematicians, is a way to hell. But it became modish to do so. 
Moreover, many arguments (used by Marek Loužek) hold only conditionally (and nearly only) for social sciences ${ }^{13}$ and they are not valid for natural sciences (leaving aside mathematics as the only one exact science). Finally, at many places it is intuitively clear that author see the discussed problem(s) from the point of view of the philosophical doctrine which is usually called the (critical) realism, i.e. from the point of view which seems to be - at least in the last decades - more and more problematic (see e.g. Prigogine, 1982, 1997 or Prigogine and Stengers, 1977, 1984 or even Popper, 1957, 1972), especially in social sciences. E.g., we can more or less reconcile with the idea that the gravitation exists (as such - nobody of course cannot hesitate that the Sun and planets attract each other or that the stones fall on Earth) but still the gravitation can be only a general abstraction, i.e. a "roof label" (or "covering notion" or "projection limit", if you want - as we explained it above) for all these events; even the fact that we are able to give a mathematical formula allowing to predict speed of the fall, does not prove anything about the existence of it. On the other hand, it is clear that the "frontier" between the (critical) realism and the instrumentalism is pretty narrow, narrower than razor edge. Returning to our example with the gravitation, the (critical) realism claims that it "exists" but it is not able - I think to give any acceptable definition what the word "exists" means, while the instrumentalism claims also that it exists and it is able to give the definition how gravitation exists, definition nearly in a way as e.g. the projection limit is defined in mathematical analysis. All after, when one try to learn that philosophers assume what the critical realism and the instrumentalism really are and how they change their opinion, one cannot depress the idea that it is similar to the history of opinions on the Darwin-Wallace theory of evolution. This theory was for a long period assumed to be a proof of nonexistence of God and over a night it has become the proof of His existence, sometimes even for the same people. Nevertheless, some difference between these two doctrines exists. In the (critical) realism we have no free will to decide what should be investigated - we only discover e.g. some (natural) laws which existed from very first second of Universe. Sometimes these laws, their characters are described in such a way that they exist even independently of existence of Universe (it is "before" it?). If we adopt the position of instrumentalism we decide what to select for an effective description of world, moreover being able (relatively) simply explain how it exists and finally having no problem how long it exists (similarly as we do not bother how long the continuous function exists), etc.

Sometimes some arguments trying to support the (critical) realism adopt the scheme of the "verification of a theory" (and consequently the existence of "objects" or "notions" they employ) by experiments. E.g. Albert Einstein believed that the observation of parallax of light of stars verifies his theory of relativity. However - as any student of statistics knows and as Karl Popper (1972) mentioned it - any physical, chemical etc. experiment (which is assumed to confirm by its result(s) that a theory is valid) is only a statistical test of a hypothesis, result of which can be either: Hypothesis is rejected or non-rejected, but not confirmed (because the result(s) of experiment can be explained potentially by some other theory). But in (social) sciences some (many?) notions (as e.g. responsibility of a person or even such thing as inflation) is difficult to explain how they exist, not how they work or how they are - or are to be - measured, but what they really are. Let me recall one on the nicest

13 And even there, they can have only limited legitimacy because part of social sciences became, in fact, part of mathematics, as econometrics, computational politology, numerical methods of sociology, etc. 
examples how difficult it is to explain what the word exits really means, let me recall Ilya Prigogine's explanation what is the time, what is its character, in his famous Tanner lecture (Prigogine, 1982). He did it in an indirect way over the notion of (ir)reversibility, so again more or less by means of how it works.

That's all what I assumed important to say as a "foreword" to specify how the text which follows was meant. Now, I'll try to give a couple of examples of spots of text of paper where I think the author's claims are (rather) questionable, or at least I would express them in a more modest way.

At the beginning of paper Marek Loužek wrote (in the original draft which I had in my hands, it was on page $\left.2^{10}\right)^{14}$ : Science brings reliable knowledge of the objective world and sociology focuses on examining the social and cultural context, which benefits or harms the scientific investigation ${ }^{15}$.

E.g. Hiram Bentley Glass, President of the American Association for the Advances of Science, wrote: As long as science is a human activity, carried on by individual man and woman and by groups of men and women, it must at bottom remain inescapably subjective. Similarly at half of 19th century Immanuel Kant recognized that: When Galileo Galilei "listened" to Nature, he did not listen as a pupil to the professor but as an inquisitor of torture law. Galileo Galilei had subjected the Nature to an inquisition. He had idealized Her i.e. he had crippled Her so that at the end She was willing to speak the language, he wanted to listen, the language of mathematics, see Popper (1972). So, it is problematic to speak about the reliable (or even objective) knowledge, although it can be - at least in some sense - unbiased, neutral with respect to all our personal beliefs ${ }^{16}$, etc., but it is far away from being objective. If an estimator is unbiased with respect to some framework, it can be pretty biased with respect to some other one. In other words, our (economic) knowledge can be quite good and helpful under some circumstances and completely useless in other situations.

Page $2_{5}$ : It is a world with clear existence of economic explanations for individual behaviour just as for social phenomena.

Let us take an example of the blessed Teresa of Calcutta, commonly known as Mother Teresa. I hesitate that economic theory can explain her behaviour, at least not main stream of economics and any explanation will be questionable, except of some from the region of metaphysics. It is similar when we can explain some other features of our behaviour, e.g. where the love or friendship came from. We should listen to theories of, e.g. Tomáš Halík or Marek Orco Vácha who have theories from the second system of human understanding the world - the metaphysics ${ }^{17}$. These theories can be viewed as to be very similar to mathematical theories, based on some "system of axioms" (e.g. Ten Commandments),

14 In the next text I'll drop the words Marek Loužek wrote ... and I'll refer only to page ${ }^{\text {row }}$ (or page ${ }_{\text {row }}$ ), although it is not very helpful for the reader of this paper; on the other hand, it supports some intuitive feeling of discussion with some text which was probably - at the moment when you read this text - already a bit (or even substantially) modified.

15 The bold words in all quotations are those which seemed to me to be questionable.

16 The English written literature uses sometimes the word objectivised.

17 The metaphysics can be assumed - for the purpose of this text - to be created by texts mostly in the form of myths which never happened but which are permanently happening, consider e.g. the myth of the Escape from Egypt which is today taking place in Eastern Europe when we are still on a way of escape from slavery of Communism. Similarly as in that myth some people started to yearn for the kettles full of meat, giving them priority before the freedom. 
"definitions" and governed by some "logical" rules $^{18}$ having even ability to predict with statistically verifiable percentage of good forecasts. Both these men naturally explain their theories as if they revealed truth but we can view them as abstract theories - similarly as in mathematics and we can leave on reader or listener how he/she accept them ${ }^{19}$.

Page $3^{23}$ : Its main problem is, how, with a given expenditure of money, time, and energy, to obtain the most valuable addition to our knowledge?

I never hear from any my colleague (mathematicians, demographers, economists, theologists or philosophers) to think about such thing. They are just curious what is an answer on this or that question and of course, they need to obtain some financial support by grants but they do not think which research will be the "most profitable". All after, even the author of the reviewed manuscript surely did not think what is the most profitable in (theoretical) economics today, otherwise he would have written a paper on some problem from mainstream and he then tried to publish it in a journal having an extreme impact factor. But he wrote a paper, I believe, he felt that he has to write it, the work on it was for him a pleasure, etc., so it had nothing to do with cold, emotionless calculation of the largest profit.

Page $4_{20}$ : And thus the institution known as the market, to the extent that it involves such competition, seems to be an appropriate model for trying to understand how knowledge, as well as other forms of wealth, increases.

Nearly any knowledge may be important goods and it brings an advantage. But in the modern world, especially in the economic competition much more important are skills and competencies of people. And that is what the good universities teach their students, independently whether they listen to the "story of economics or of quantum theory". And, as I have already written it, the increase of knowledge is - I think - the result of endeavour of researchers who are curious what answers on these or those questions they can obtain, not taking into account what impact it would have. There are even researchers who want to know but for whom it is irrelevant whether other accept their findings or not. For them it is sufficient that they know.

Page $6_{18}$ : Debates among scientists about their theories can be just as strong, emotional and sometimes even vile like political clashes.

First of all, maybe it is possible in soft "sciences". It is due to the fact that: We can prove by words anything, especially just the opposite ${ }^{20}$. In mathematics, e.g., the proof is valid or not and if we leave aside (for a while) some consequences of famous Gödel's incompleteness theorems, we can just declare (with Sir Karl Poper) the scientific theory as a theory which can be tested by empirical material and either rejected or not-rejected

18 The converted commas should remind well known text: For my thoughts are not your thoughts, neither are your ways my ways, declares the Lord. For as the heavens are higher than the earth, so are my ways higher than your ways and my thoughts than your thoughts. Isaiah 55:8-9.

19 Even then there can be pretty large difference how we accept them. If I really take the idea that the acceptance of them is a step of my free decision and not something which is "given" as such, I am free to try to accept for a while some "other system of metaphysical axioms" to see, to understand and to accept the world in a different way from my own. One can then object that then the accepted system of "axioms", is not so obligatory for me as it would be if I take it as "given", as e.g. revealed by God. I feel it in a just opposite way - freely accepted system of axioms (for my behaviour, etc.) is for me much more obligatory then something which is as "natural law", i.e. for which I cannot decide by free "will" (converted commas indicate that the word "will" should be taken not in a rational way but in a vague way, so what I can't "explain" why I have decided as I did). 
but there are no emotions connected with it. The science is not objective but it should be completely impersonal, unbiased and calm. I suppose that these features are ones of the most important, the most natural features of science - they characterize the science (of course not exhaustively, but significantly).

Page $6_{2}$ : The second difference is that while physical sciences study topics that are all non-controversial, social sciences study subjects, in which the general public has a vested interest and which have a strong ideological or moral background. When a social scientist finds out that a theory is not in accordance with widely accepted opinions, he will rather revise it because he cannot expect any popularity with his colleagues.

First of all, if we formulate some problem in such a way that it has some ideological or moral content (or background) then we should ask whether it is still scientific problem. As I already stressed I assume (together with Ilya Prigogine or probably also Karl Popper) that the objectivity of science - as it was understood by the Renaissance and the Age of Enlightenment - is an illusion. But even then I believe that the science should be impersonal, it should not have any ideological burden, any religious preconception, etc. I quite well remember how we were taught in basic school that the results of Fascist scientists are bad. But even during this horrible part of human history German mathematicians proved the theorems which are valid. The "scientific" results obtained during the Second World War which are not nowadays valid were not scientific from very beginning. They were not achieved by scientists but by deceivers. All after, American writer Haakon Maurice Chevalier (1959) wrote a book about Robert Oppenheimer (commonly assumed to be father of atomic bomb; in fact Robert Oppenheimer was a "scientific manager" of the project in Los Alamos and more or less the "true" father of bomb was Italian Nobel prize winner Enrico Fermi) in which he stressed that when we accept in science as relevant some ideological, religious, moral etc. criteria, we are inevitably on the way to hell ${ }^{21}$. It is just one of very clear feature of science that it is neutral to all such ideas. To be more explicit: We - as researchers - have to solve problems containing the objective function ${ }^{22}$ which has some arguments (variables), some constraints, etc. and it returns some response, i.e. function e.g. from a p-dimensional Euclidean space to some q-dimensional Euclidean space and their concrete shape and content should be specified only when we apply the theory. Then they, of course, obtain - e.g. in a case study - some political, moral, etc. background but it is the question of submitter of task (e.g. politicians, social workers, etc.) to say which objective function should be taken into account in given extremal problem ${ }^{23}$ or which theory is to be applied. In other words, a decision which concrete objective function is to be selected in a given application, has to come from the second or the third collections of human tools of "explaining" the world

21 It does not mean that we - as scientists and/or teachers - should not have any philosophical, political, religious, etc. ideas and even to discuss them with our colleagues and students but we should leave them aside whenever we discuss scientific problems.

22 The word "objective" is here used as terminus technicus from mathematics (from optimization), it is function saying what is preferable, what brings a desirable consequences, large profit in given sense, etc. but all these things are on an abstract level given numerically without any content from real world, without any connection with "objectivity" as it was understood by philosophy of science, especially by (critical) realism.

23 The extremal problem is a (formalized mathematical) problem looking for maximal "profit" or minimal "loss". 
(as they were discussed above). E.g. if such decision comes from region of metaphysics, it was made on a selected system of axioms (e.g. on the Ten Commandments) and it has nothing to do with science. If we borrow for a while e.g. the notions from one handicraft, the furniture-making, the science produces tools as saws, drills, jake-plain, chisels, etc. but it does not say whether the tables or chairs are to be made by them. It is question of carpenter (politicians, decision-makers, etc.).

Page $7^{5}$ : Unlike in physical sciences where a minority can persuade the majority about the truthfulness of their opinions by showing that the special innovation works, the matter is more complicated in social sciences. In order to achieve innovation, a social scientist in a democracy must persuade the majority.

This is very similar to the previous topic. If we really do science then it is not about persuading somebody (by words) but about convincing him/her by proof (either mathematical or empirical; the former alternative applies in mathematics, the latter in any other science ${ }^{24}$ ). In other words, the science has nothing to do with the democracy (of course, in non-democratic political framework the science can be under oppression and such empirical proof can be depressed or forbidden by force but it can change nothing on the fact whether the assertion in question is valid or not).

Page $8^{23}$ :... the tenacious resistance of scientists to accepting new ideas can be explained by investments into human capital and aversion to risk. A recognized scholar protects his own capital capable of bearing revenue because he has mastered a certain body of knowledge. This capital would be reduced, if the scholar's knowledge became obsolete as a result of a general acceptance of a new theory.

When I read the previous lines I hesitate whether I live in the same world as authors of them. I admit that in the market economy some experts (not scientists) can behave according to this assertion. I refuse to believe that Bernard Bolzano or Albert Einstein can behave in such a way. I think that it is just a feature of real personality in science that he/she supports new ideas even in the case that it is "inconvenient" for him/her, e.g. that a new method of my colleague appeared to be more efficient than mine. Of course, there are well known cases of resistance to the new results in science. Probably the most famous is already mentioned Gödel's incompleteness theorems. He reached this results in thirties (of past century) and there are still persons who do not believe that the results is valid, looking for an error in proof. But this resistance has nothing to do with some personal advantages - this resistance has its roots in (uncritical) belief that in mathematics we can prove that given assertion is either true or false.

On the other hand, the "story of Gödel's incompleteness theorems" is a nice example of ethical behaviour of other scientist - David Hilbert. Hilbert's idea was that when we start to build up the mathematics in an axiomatic way, we learn - at the "end" - the "whole truth". But Gödel's result indicated that Hilbert's idea cannot be completed. Despite it, it was just David Hilbert who insisted that Gödel's result has to be published.

24 We are aware that there are still problems - even when we specify the problem in a (say) semiformalized form. Our solution, even obtained in the mathematical framework will depend on what we have decided to measure or what data we have collected, what method of data-processing we have selected. But these problems can be - at least in an acceptable level of uncertainty - solved e.g. by application of several methods of processing data. If we obtain approximately the same results, we solved well defined problem. But it is a discussion which is beyond the scope of this paper. 
Although many ideas I have expressed in this text may seem at the first glance skeptical, they are not. Many people would be disappointed or even frustrated when even only hearing about an idea that science cannot be objective or that at the "heart" of science, in mathematics, we can meet with assertion which cannot be proved to be valid or false. But every coin has two sides. Let us illustrate it on the example of Gödel's result. Approximately twenty years later Jerzy Bronowski (1951) showed that if there are some assertion which cannot be proved, on a base of any axiomatic system by means of formal logic, to be true are false, that in a concrete situation (universe) they can be valid and in other situation it can be false. Then taking into account (potential) frequency of valid cases, we can assign to such assertion a probability that it is true. He claims that it is an indication that even the mathematics has a stochastic character. Let us recall that Alexander Keewatin Dewdney wrote in (2004) about the mathematics:

While it has many features of a language - mainly notation that looks like Egyptian hieroglyphics to non-mathematicians - there must be more than mere language going on. We still have to account for amazing success of mathematics as a description of physical reality. The precision of so many theories of physical reality may hint at a deeper truth, that mathematics is a major structural foundation of our universe.

Then we can conclude that our Universe has a nondeterministic character - although we cannot never learn it sure (see again discussion between Albert Einstein and Niels Bohr). Of course, it is not new idea (see Prigogine, 1997, 2003) but only a further reason supporting it.

At the end I would like to stress that due to the fact that Marek Loužek's paper belongs in the region of "narrative sciences" (i.e. the text is not based on some definitions and it is not governed by some logical rules and hence we can prove by words anything, see Thales above), all my comments are question of taste and they expresses my private opinions ${ }^{25}$. Moreover, I am aware that the text of my paper is written in a bit provocative way, exaggerating somewhat some points of view. I do it so, trying to provoke readers to think about problems which the researchers and teachers do not think frequently about (or do not think about at all), intuitively assuming that they are clear ${ }^{26}$. I am also aware that the text is (significantly) influenced by the fact that I am mathematician. Hence the most illustrative examples, especially those demonstrating how unsatisfactory and deficient the common sense is, are (more or less) mathematical. On the other hand, one of the most important role of mathematics (if not the most important at all) is to show us how deceptive, tricky and precarious can be unformalized way of "proving" something (or even anything) and to learn us to think in an abstract way, abstract as far as possible, because it usually immediately indicates where we make some improper steps of thinking due to relying on commonly accepted but frequently wrong short-cuts.

Finally, I beg the readers for mercy with the text because I am used (for the whole my professional carrier) to write mathematical texts. Such text is relatively easy to keep unambiguous (due to unique, explicit sense of notions) with a clear line of logic

25 Lion Feuchtwanger wrote in one of his novel: My philosophical point of view is imperative only for me. To make it obligatory for others, such pretentious demands I leave to politicians and empty heads. In fact I had no chance to prove that hypotheses of Marek Loužek are to be rejected. It could be done only if these hypotheses would be given as (mathematical, statistical) formalized hypotheses (about some parameters of some model(s)).

26 The problem: "What is a connection between our models, formalized or narrative, to the real world?" 
considerations. As I mentioned "We can prove by words anything, especially just the opposite." If we take this sentence really seriously, narrative text - without rigorous definitions - can be hardly really scientific. Of course, the last sentence exaggerates but is not very far from truth.

\section{References}

Atalay, B. (2006). Maths and Mona Lisa: The Arts of Science of Leonardo da Vinci. HarperCollins Publisher, published by arrangement with Smithsonian Books, NY.

Bronowski, J. (1951). The Common Sense of Science. Heinemann, London, (2nd Ed. in 1978 Library of Congress Catalog Card Number A55-9924).

Dewdney, A. K. (2004). Beyond Reasons: Eight Great Problems That Reveal the Limits of Science. Wiley, NY.

Halmos, P. R. (1981). Applied Mathematics is a Bad Mathematics. Mathematics Tomorrow, Springer Verlag, New York, 9-20.

Popper, K. R. (1957). The Poverty of Historicism, London, Routledge \& Kegan Paul, Ltd.

Popper, K. R. (1972). Objective Knowledge. Oxford Clarendon Press.

Prigogine, I. (1982). Only an Illusion. The Tanner Lectures on Human Values, Jawaharlal Nehru University, December 18, 1982.

Prigogine, I. (1997). The End of Certainty. New York: The Free Press

Prigogine, I. (2003). Is Future Given? World Scientific.

Prigogine, I., I. Stengers (1977). La Nouvelle Alliance. SCIENTIA, 1977, issues 5-12.

Prigogine, I., I. Stengers (1984). Out of Chaos. William Heinemann Ltd 1984 